\title{
Fresh Autogenous Rib Cartilage Graft to the Malar Process of Rats with and without Removal of the Perichondrium: A Histological Study
}

\author{
Silas de TULIO $^{1}$, Tetsuo OKAMOTO ${ }^{2}$ \\ and Mario Francisco Real GABRIELLI ${ }^{3}$ \\ (Received 30 April and accepted 19 June 1991)
}

Key words: cartilage grafts, autogenous, perichondrium

\begin{abstract}
A comparison was made of autogenous grafts of rib cartilage with and without removal of the perichondrium, applied to the malar process of rats. Seventy-two male albino rats were divided into two groups according to the kind of graft received by each animal. The experimental periods were 5, 10, 20, 30, 60 and 120 postoperative days. The results showed that, in the control group, the grafts maintained their vitality for the whole experimental period and the perichondrium was biologically integrated into the host bed. Appositional growth was also observed. The treated animals showed intense resorption of the grafts and more intense bone neoformation. The newly formed bone was in intimate contact with the graft in both groups.
\end{abstract}

\section{Introduction}

Cartilage is a very suitable graft material because of its nutritional characteristics, low cellularity and high anaerobic metabolism, which allow survival during fairly long periods of hypoxia ${ }^{[1,2]}$. Also, it does not require functional stimuli to maintain its bulk, nor contact with the same kind of tissue for survival ${ }^{[3,4]}$.

In oral and maxillofacial surgery, the use of cartilage fragments from the trachea $^{[5,6]}$, nasal septum ${ }^{[7]}$, costochondral junction ${ }^{[8]}$ and epiphiseal cartilage ${ }^{[8,9]}$ has become more frequent. Among these, hyaline costal cartilage seems to show the highest graft survival rates after transplantation ${ }^{[4,10-12]}$.

Humphrey and White ${ }^{[12]}$ considered the importance of the protective nature of the cartilagenous matrix, which prevents invasion by inflammatory cells from the host.

TULIO ${ }^{[13]}$ observed that costal cartilage grafts transplanted to the mandible of rats, on a receptor bed composed mostly of cortical bone and without any means of fixation, survived for up to 120 days and showed some growth.

\footnotetext{
1 Post graduate (doctor) in oral surgery, Dental School of Aratuba, UNESP

2 Professor, Division of Oral and Maxillofacial Surgery, the Dental School at Araçatuba, UNESP.

3 Professor, Division of Oral and Maxillofacial Surgery, the Dental School at Araraquara, UNESP.

To whom all correspondence should be addressed: Dr. Tetsuo OKAMOTO, Division of Oral and Maxillofacial Surgery, the Dental School at Araçatuba, UNESP., BRAZIL.
} 
Several authors consider that the perichondrium is fundamental for graft survival and appositional growth ${ }^{[13-16]}$. Therefore, the present study was designed to evaluate in detail the role of the perichondrium in the behavior of autogenous costal grafts.

\section{Materials and Methods}

For the present investigation, 72 male albino (Rattus norvegicus var albinus, Wistar) were employed. The animals weighed $300-350 \mathrm{~g}$ and were maintained on a solid diet, except for the first $24 \mathrm{~h}$ postoperatively. They were divided into two groups according to the type of graft used, with or without the perichondrium.

\section{Graft removal}

Under general anesthesia induced by intraperitoneal injection of $50 \mathrm{mg} / \mathrm{kg}$ body weight thionembutal, the left thoracic and malar regions were depilated. The animals were then positioned in a supine position and immobilized by the head and extremities, allowing access to the areas of interest. A no. 15 blade was used to incise the skin and subcutaneous tissue over the last rib, with an extension of approximately $10 \mathrm{~mm}$. The muscle plane was divided with scissors and a $5 \mathrm{~mm}$ segment was removed from the last rib. A no. 11 blade was then used to remove soft tissue debris, involving the perichondrium in half of the specimens (36 animals), and the graft material was placed in saline, while the host bed was prepared.

\section{Grafting procedure}

While the rats were still under general anesthesia, a $10-\mathrm{mm}$ skin and subcutaneous incision was made over the region inferior to the left malar bone. The muscle plane was divided with scissors and the periosteum was incised. A lowspeed no. 703 burr was then used under irrigation to prepare a cavity of about $4 \times$ $2 \mathrm{~mm}$ on the malar process. The cartilage graft was then adapted to the cavity, and the grafting procedure took approximately $7 \mathrm{~min}$ for each animal in both groups. All surgical wounds were sutured with 5-0 polyvicryl. All animals then received an individual intraperitoneal dose of 16,000 i.u. penicillin $\mathrm{G}$ benzathine.

\section{Histological preparation}

Six animals in each group were sacrificed after 5, 10, 20, 30, 60 and 120 days postoperatively. The zygomatic arches were dissected out en bloc, fixed in $10 \%$ formalin solution for $24 \mathrm{~h}$ and then subjected to routine laboratory procedures to obtain 6-mm thick semi-serial sections, which were stained with hematoxylin and eosin for histological analysis.

\section{Results}

\section{5 days}

Control group: The grafted cartilage, apparently vital, was surrounded by neutrophils, and moderate numbers of lymphocytes and histiocytes and small blood clots were seen. In other areas, slight to moderate proliferation of capillaries and fibroblasts was evident.

Treated group: The cartilage was apparently vital. Close to the graft, an intense neutrophilic infiltrate, small amounts of blood clots and moderate numbers 
of histiocytes were found.

\section{0 days}

Control group: In all specimens, the cartilage was vital (Fig. 1) and evident growth was observed in some cases. Poorly differentiated newly formed connective tissue, infiltrated by moderate numbers of lymphocytes surrounded the grafts. Some histiocytes and plasma cells were also seen in the same areas.

Treated group: Part of the cartilage was resorbed and the remaining portion was apparently vital. Fibroblast-rich connective tissue, infiltrated by moderate numbers of lymphocytes, was associated with the grafts (Fig. 2). In most specimens, the connective tissue close to the cartilage exhibited numerous multinucleated cells and an intense infiltrate composed of histiocytes and lymphocytes.

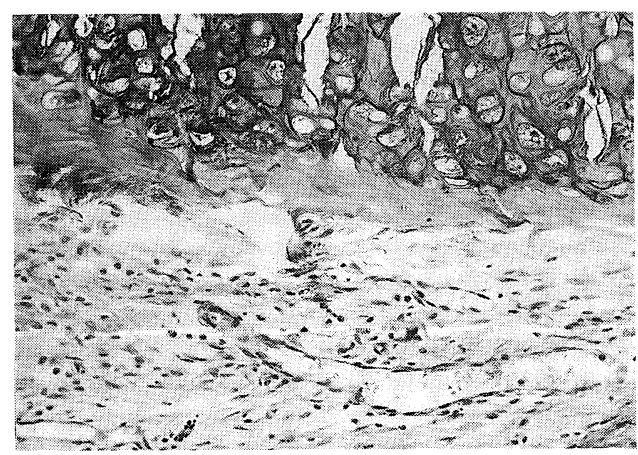

Fig. 1 Cartilage grafted without removal of the perichondrium, showing signs of vitality. 10 days. Hematoxylin and eosin stain (x160)

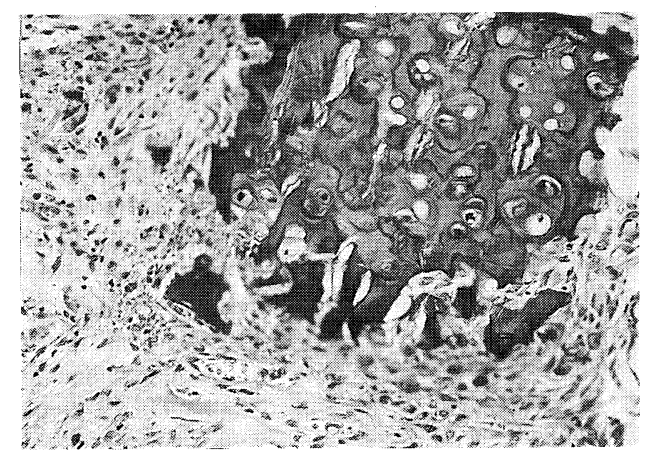

Fig. 2 Cartilage grafted after removal of perichondrium. Fibroblast-rich connective tissue is infiltrated by moderate numbers of lymphocytes. 10 days. Hematoxylin and eosin stain (x160)

\section{0 days}

Control group: After 20 days, the cartilage was vital and showed definite growth in most cases. Adjacent to the material, fibroblast-rich connective tissue, infiltrated by occasional lymphocytes, was observed (Fig. 3). In one specimen, the perichondrium showed slight discontinuity and newly formed connetive tissue filled the area affected. The latter showed well vascularized connective tissue and 
newly formed trabeculae.

Treated group: The cartilage showed only a few cells apparently vital. The grafts were associated with well vascularized connective tissue (Fig. 4) with small

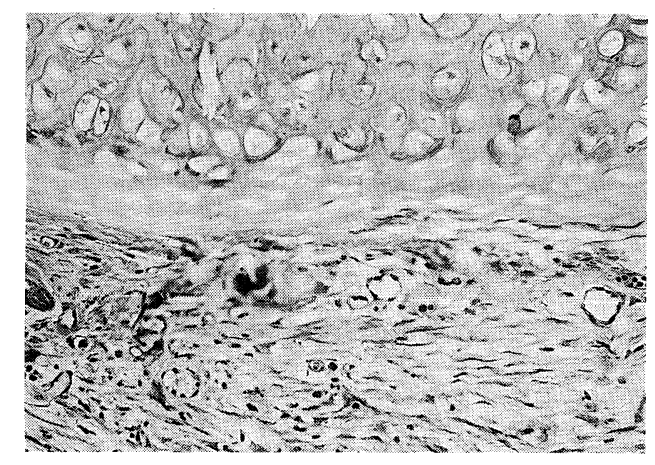

Fig. 3 Cartilage transplanted with maintenance of the perichondrium after 20 days surrounded by cellular connective tissue infiltrated by a few lymphocytes. Hematoxylin and eosin stain (x160)

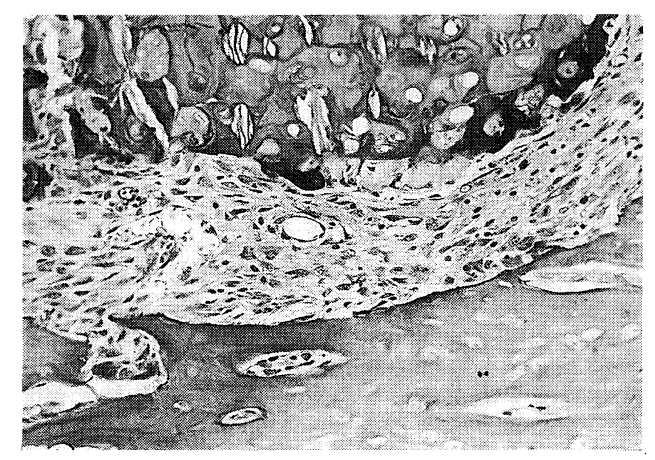

Fig. 420 days. Cartilage grafted after removal of the perichondrium is associated with well vascularized connective tissue. Hematoxylin and eosin stain (x160)

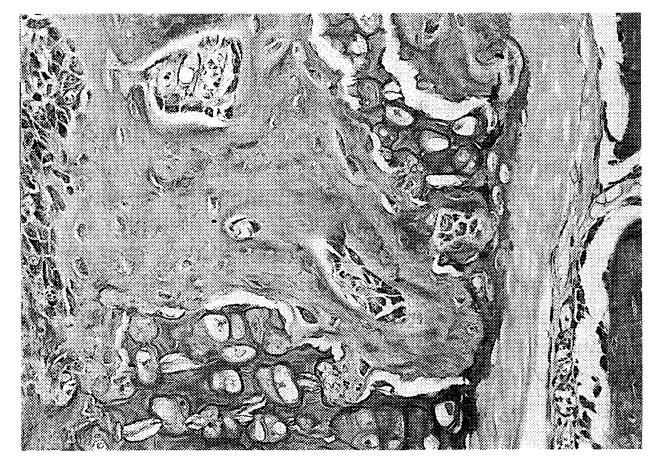

Fig. 520 days. Cartilage grafted after removal of perichondrium, showing several resorbed areas filled with newly formed trabeculae. Hematoxylin and eosin stain (x160) 
numbers of lymphocytes and some multinucleated cells. The grafted tissue was resorbed in several areas, which were filled with newly formed trabeculae (Fig. 5) or well vascularized fibroblast-rich connective tissue.

30 days

Control group: The cartilage was vital and showed slight to moderate growth. Fibrous tissue was present parallel to the perichondrial surface in most cases. Newly formed trabeculae wese evident adjacent to the perichondrium.

Treated group: The cartilage, with few apparently vital cells, shows several areas of resorption. Besides the newly formed bone which partially filled the resorption lacunae, connective tissue was found adjacent to the material. Some multinucleated cells were present. In some cases, the graft had been grossly resorbed and numerous multinucleated cells were seen.

\section{0 days}

Control group: After 60 days, more intense growth was found (Fig. 6) in most specimens, in comparison with the previous group. Several times, the newly formed cartilage was seen in proximity to newly formed bone. In other instances, the graft was close to fibrous connective tissue.

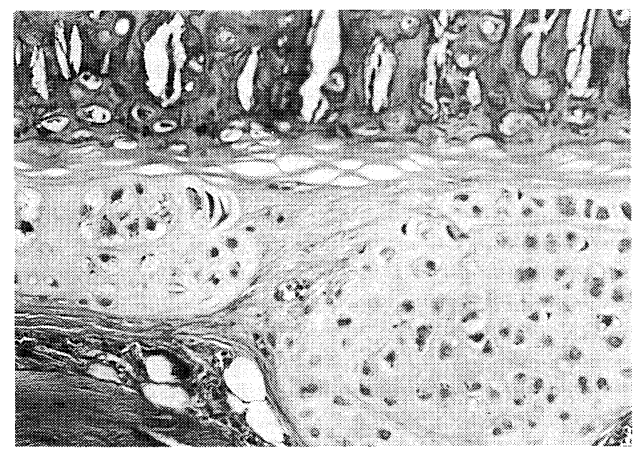

Fig. 6 After 60 days, there is more intense growth of the cartilage transplanted with perichondrium, as compared with the previous period. Hematoxylin and eosin stain (x160)

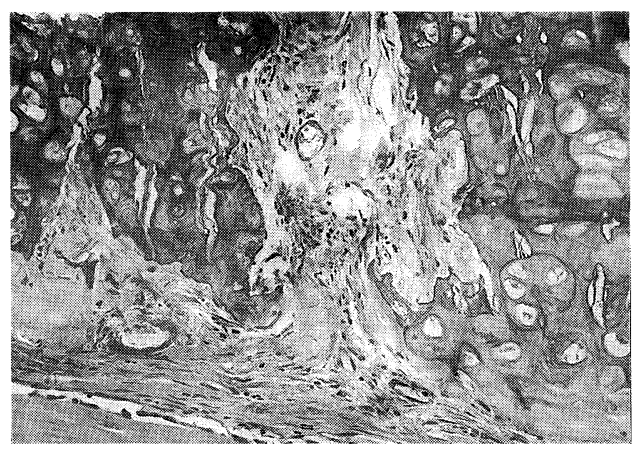

Fig. 7 After 60 days, $2 / 3$ of cartilage transplanted after removal of the perichondrium is resorbed, and loose connective tissue has substituted the grafted material. Hematoxylin and eosin stain (x160) 
Treated group: In most cases, approximately $2 / 3$ of the cartilage had been resorbed, and loose connective tissue (Fig. 7) or small bone spicules had substituted the grafted material. In one specimen, the graft remained almost whole, apparently non-vital and displayed small areas of resorption.

\section{0 days}

Control group: After this, the longest period, the grafts had grown a little more in some specimens, compared with the previous stage. Between cartilage and bone, a small space was generally present (Fig. 8).

Treated group: In all specimens, small portions of the graft were localized among newly formed trabeculae (Fig. 9).

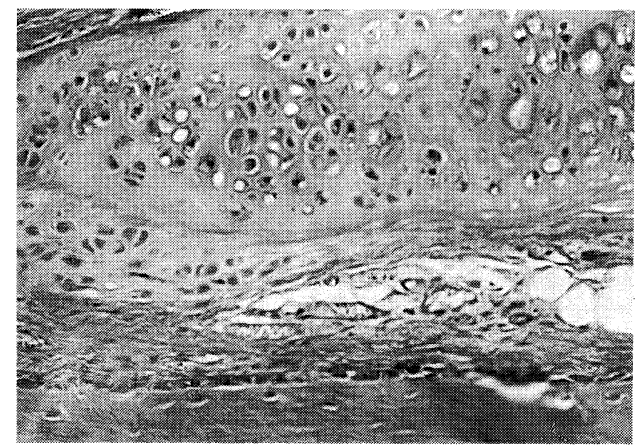

Fig. 8 Growth has increased a little after 120 days for specimens transplanted with perichondrium, as compared with the previous stage. Hematoxylin and eosin stain (x160)

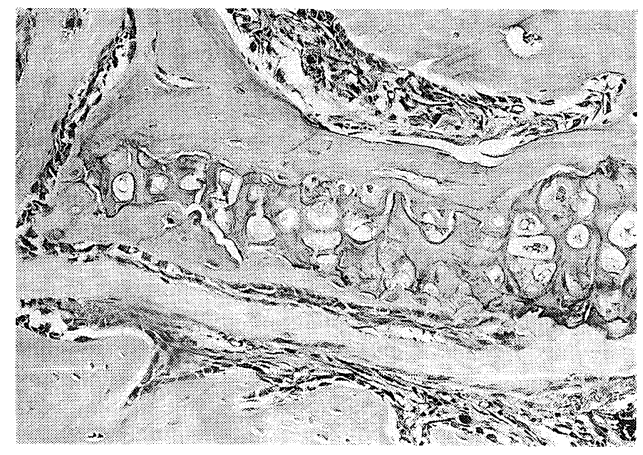

Fig. 9 Cartilage transplanted after removal of the perichondrium after 120 days. Small portions of the graft are seen among newly formed trabeculae. Hematoxylin and eosin stain (x160)

\section{Discussion}

After the initial stage characterized by acute inflammation due to surgical trauma, both the cartilagenous matrix and perichondrium were sound and in close contact with newly formed connective tissue, indicating survival and acceptance of the graft $^{[17]}$.

The treated specimens were also well accepted, as one would expect for 
autogenous material, although the proportions of resorption became greater with time. In fact, deterioration of cartilage after grafting is not well characterized, and the exact mechanism involved is unclear ${ }^{[18]}$.

Although several workers have studied the role of the perichondrium in cartilage grafting, the question of graft growth is still controversial. EISEMANN ${ }^{[19]}$ carried out an experimental study in rabbits, where auricular cartilage was grafted with or without perichondrium, or isolated perichondrium, into the pelvis musculature, neck musculature and rib. The author demonstrated that both kinds of graft grew both in extent and thickness, indicating that the perichondrium was not necessary for growth of the grafted cartilage. The chondrogenic potential of free perichondrial grafts thus seems to be inconsistent. In the present study, growth was always associated with the presence of the perichondrium. TAKAI ${ }^{[20]}$ observed induction of cartilage neoformation from host tissue, employing auricular cartilage grafts. In our study, all the growth observed in the control group was appositional at the expense of the inner perichondrial layer. However, the perichondrium was not responsible for bone neoformation around the grafts. Endochondral ossification was not found in the control group, as suggested previously ${ }^{[8,21,22]}$. Bone neoformation was more intense close to the treated grafts, and some morphological aspects appeared to suggest endochondral ossification in such cases. In fact, SCHAFFER ${ }^{[22]}$ described higher indices of ossification after transplantation of devitalized cartilage. SouzA ${ }^{[1]}$ observed in rabbits that the degree of trauma of the perichondrium is directly proportional to the resulting alteration of metabolism in newly formed cartilage, with degeneration, necrosis and bone neoformation. It is probable that removal of the perichondrium in the treated group, with associated trauma and devitalization, was responsible for the higher rates of resorption and bone neoformation in such cases, and therefore perichondrial removal should be done when faster substitution of grafted material is required.

\section{Acknowledgments}

This work was supported by Fundeção de Amparo à Pesquisa do Estado de São Paulo (FAPESP).

\section{References}

[1] Souza, L. C. M., Aguiar, A. F., Valle, E. C. N., Behmer, A. O., Brunetti, C. and Lodovici, O.: Atividade condrogênica de enxerto e retalho de pericôndrio: formação de cartilagem plana e moldada. Estudo experimental, Rev. Hosp. Clin. Fac. Med. S. Paulo, 36, 114-18, 1981

[2] Laskin, D. M. and SARnat, B. G.: The metabolism of fresh transplanted, and preserved cartilage, Surg. Gynec. Obst., 96, 493-499, 1953

[3] Goode, R. L.: Bone and cartilage grafts: current concepts, Otolaryngol. Clin. North Am., 5, 447-455, 1972

[4] Kazanjian, V.H. and Converse, J. M.: Surgical Treatment of Facial Injuries, 3rd ed., Baltimore, Williams \& Wilkins, vol. 1, 5614, 1975

[5] Inoue, T.: The "cartilage effect" on healing wounds. A sutdy of the specificity of the phenomenon, Archs. Surg., 82, 432-434, 1961

[6] Prudden, T. M.: Experimental studies on the transplantation of cartilage, Am. J. med. Sci., 82, 360-370, 1881. Apud: Arch Otolaryngol, 109, 469-472, 1983 
[7] Shaffer, E. M. and Packer, M. W.: Bone regeneration: cartilage and tooth grafts in periodontal pockets, Dent. Clin. N. Am., 6, 459-469, 1962

[8] URist, M. R. and MacLean, F. C.: Osteogenic potency and new bone formation by induction in transplants to the anterior chamber of the eye, J. Bone Jt. Surg., 34a, 443-476, 1952

[9] Lacroix, P.: The Organization of Bones, Philadelphia, Blakiston, 145, 1951

[10] Peer, L. A.: The fate of living and dead cartilage transplanted in humans, Surg. Gynec. Obst., 68, 603-610, 1939

[11] Dupertuis, R. W.: Actual growth of young cartilage transplants in rabbits, Archs. Surg., 43, $32-63,1941$

[12] Humphrey, J. H. and White, R. G.: Imunologia Médica., 3rd ed., Rio de Janeiro, Guanabara Koogan, 639, 1972

[13] Tulio, S., Oкамото, T. and Gabrielli, M. F. R.: Free autogenous costal cartilage grafts to the mandible of rats, in press, 1990

[14] Junqueira, L. C. and Carneiro, J.: Histologia Básica, 3rd ed., Rio de Janeiro, Guanabara Koogan, 122-131, 1974

[15] Ham, A. W. and Leeson, T. S.: Histologia, 2nd ed., Rio de Janeiro, Guanabara Koogan, 639, 1972

[16] Breadon, G. E., Kern, E. B. and Neel, H. B.: Autografts of uncrushed and crushed bone and cartilage. Experimental observations and clinical implications, Archs. Otolar., 105, 75-80, 1979

[17] Carvalho, A. C. P. and Окамото, T.: A histological study of cartilage autografts and allografts placed in dental sockets of rats, J. Oral Surg., 37(1), 11-15, 1979

[18] Rodrigo, J. J., Sakovich, L., Travis, C. and Smith, G.: Osteocartilagenous allografts as compared with autografts in the treatment of knee joint osteocartilagenous defects in dogs, Clin. Orthop., 134, 342-349, 1978

[19] Eisemann, M. L.: The growh potential of autograft cartilage. An experimental study, Archs. Otolar., 109, 469-472, 1983

[20] TAKAI, Y.: Experimental study on cartilage transplantation. I. Auto-transplantation and homo-transplantation of ear cartilage in immature rabbits, Aichi Gakuin J. Dent. Sci., 11, 18-19, 1973

[21] Peer, L. A.: Transplantation of Tissue, Baltimore, Williams \& Wilkins, vol. 1, 65-137, 1955

[22] Schaffer, E. M.: Cartilage transplants into the periodontium of rhesus monkeys, Oral Surg., 9, 1233-1246, 1956 